\title{
A square in drag as concrete universal; or, Hegel as a Sketchpad programmer
}

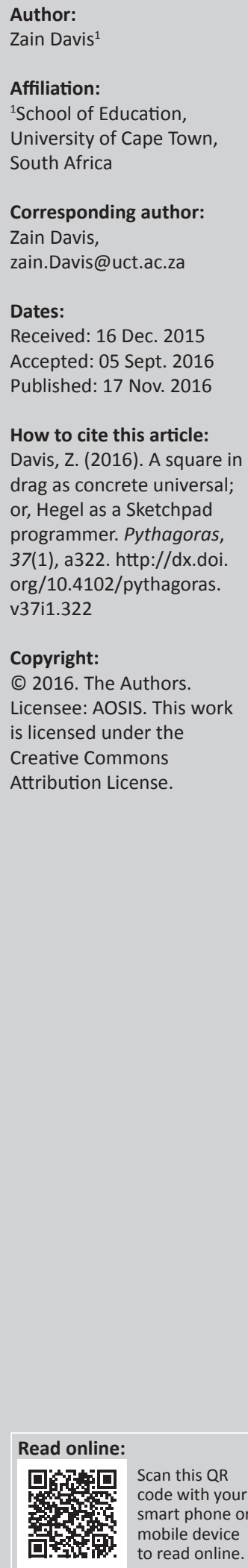

\begin{abstract}
In this article, by way of an analysis of a case of mathematics teacher training, I explore the general idea of pedagogic expectation of an alignment of pedagogic identities and specific realisations of mathematics in pedagogic contexts. The particular case analysed has a constructivist orientation, but the analytic resources brought to bear in the analysis can be used more generally for the description and analysis of pedagogic situations. The analysis is framed chiefly by the philosophical work of Georg Hegel alongside Basil Bernstein's sociological discussion of evaluation in pedagogic contexts. The argument proceeds in three inter-related parts, the first of which produces an analytic description of the discursive production of the desired pedagogic subject-in this case, a teacher/student of geometry-in which I show how explication and abbreviation are used discursively in an attempt to construct the desired teacher/student-that is, a particular pedagogic identity. The second part of the argument describes the discursive production of mathematics content in a manner intended to align content with the desired teacher/student and introduces the notion of a regulative orientation in order to grasp the differences in the mathematical work of students. The third part is a synthesis of parts one and two, showing how pedagogic identity and mathematics contents are brought together as correlative effects of each other.
\end{abstract}

\section{Introduction}

These days it is commonplace for official elaborations of national curricula to make very noticeable pronouncements on the nature of the school learner and the teacher and not only on the contents of school subjects. Curriculum-specific expectations about teachers and their learners are not something new. The main difference from the past is that ideas of who the learner and teacher ought to be are made a great deal more explicit now than was the case when social arrangements were a lot more stable and the life trajectories of individuals could be predicted and mapped out with a reasonable degree of confidence. Many of the effects on mathematics education of the social, political and economic transformations that irrupted over the course of the 20th century, spilling over into the present one, are drawn together and focused in the various realisations of pedagogic constructivism (see Dowling, 2002, p. 36ff.), that is, the use of pedagogic principles derived from philosophical positions on epistemology arguing that all knowledge held by individuals is necessarily constructed by the knower. The sticky fingerprints of pedagogic constructivism can be detected on curriculum statements, school texts and, in more complicated ways, on pedagogic practices across the globe. The conceptions of the mathematics teacher, of the student and of mathematics that derive from a constructivist frame, or even from resistances to such framing today, are rather different from the conceptions of teachers, students and school mathematics that circulated before the emergence of pedagogic constructivism. Today we have no choice but to engage with the far-reaching effects of pedagogic constructivism on mathematics education and on the training of mathematics teachers. This article is an instance of such in the context of teacher education.

One of the important pedagogic problems that we have to confront as trainers of mathematics teachers-and one which arises as an effect of the insistent hegemonic grip of pedagogic constructivism on contemporary mathematics education-is the very real potential for teachers and students to become unmoored from mathematics and drift into unproductive, incoherent solipsism as they attempt to develop skills that are intended to have the ultimate effect of encouraging and sustaining productive reflections on mathematics. Piaget's (1995) sophisticated arguments elaborating his concerns about the negative effects of egocentric and sociocentric thought on learning, along with his cautions on the dangers of educational arrangements that tend to authorise knowledge statements gerontocratically, seem to arrive in the pedagogic constructivist universe in a curiously simplistic and fractured form. The constructivist propositions 
on the impossibility of the transmission of knowledge from one mind to another are often recontextualised to pedagogic constructivism as propositions declaring the impossibility of teaching, with the expectation that the teacher no longer teaches. That is, the impossibility of the direct transmission of knowledge is transmuted into a prohibition against teaching. Where that does happen, such impossibility is often restricted only to the teacher, not to students, because it is usually accepted (implicitly or explicitly) that students are able to learn from each other, typically via some form of group-based activity, and without the pedagogic evaluations of the teacher.

The teacher who would adopt pedagogic constructivism as the central organising framework for teaching and learning school mathematics is confronted with the rather delicate task of acknowledging the student as always-already knowledgeable-but must nevertheless have the latter arrive at the realisation that they are, in fact, also ignorant-and of valuing the everyday experience of the student, yet simultaneously getting them to realise that mathematics contents are grounded in a necessity derived from mathematics rather than from either everyday experience or some social mechanism (like voting, for example). The Socrates of Plato's dialogues is the exemplary pedagogue in this regard, skilfully engaging his confident interlocutor (usually a beautiful young man) in a manner that gives impetus to the youth's journey from a confidence grounded in the apparentcertainty of experience to an acknowledgement of his profound ignorance, which Plato saw as a necessary precondition for access to knowledge rather than remaining mired in mere opinion (see Bloom, 1991).

So, how is a teacher to be trained to become a pedagogic constructivist? It appears that a favoured way of training teachers to that end is to embody the central propositions that are to structure pedagogic practice in an exemplary form of pedagogic engagement that models the practice for the neophyte. It often turns out to be the case that the trainee adopts the position of a school learner while the trainer adopts the position of a pedagogic constructivist school teacher.

The case discussed in this article is an instance of pedagogic constructivist mathematics teacher education that proceeds along the lines just sketched, revealing in the process a series of interesting features of the approach that are worth considering in some detail. However, to arrive at a more precise framing of the central issues, some or other set of theoretical resources needs to be recruited to enable us to reflect on the immediacy of the initial encounter with the empirical record of the case. It is to that task that I now turn.

\section{General theoretical frame}

In his discussion of the pedagogic device, Bernstein (1996, p. 50) arrives at a position claiming that evaluation is the key to pedagogic practice. With his use of the term evaluation
Bernstein is referring to instructor-learner interactions that include pedagogic exchanges between instructors and learners, as well as engagements with problems, tests, projects, examinations and so forth. It is in that broad sense that the term is used here. For Bernstein, pedagogic practice is necessarily saturated with evaluative acts that are continually performed by pedagogic subjects and so routinely generates evaluative judgements of the knowledge claims and statements made by instructors and learners.

Schooling can be viewed as a context in which the encounters between selected fields of knowledge and learners are staged, with pedagogic evaluation functioning as the mechanism mediating the encounter between a field of knowledge and the learner. Pedagogic evaluation marks out what are to be taken as legitimate and illegitimate learner responses to the recurrent demands on them to produce utterances-written, spoken and gestural-in pedagogic situations. What pedagogic evaluation thus inserts into the pedagogic situation is a demand for and assessment of what ought to be the content of instructor and learner activity. In other words, the staging of an encounter between the learner and a field of knowledge necessarily produces a moralising of learner and instructor.

What the ought of pedagogic evaluation proposes is a correlation of a pedagogic identity with particular realisations of content. Bernstein (1990, p. 183) announces a proposition on this specific feature of what he terms pedagogic discourse in a somewhat clumsy way, as the embedding of an instructional discourse in a regulative discourse, where the latter is a discourse of social order and is dominant. Dowling (2009, pp. 81-83) has detailed a series of problems with Bernstein's formulation of the proposition, which the interested reader can review for themselves.

The central proposition that I wish to exemplify and explore in this article is the following: the ought of the pedagogic situation is internally split between some idea, or expectation, of a specific pedagogic identity on the one hand and particular realisations of content on the other, with the pedagogic identity believed to be correlated to particular realisations of content. The particular pedagogic identities and their imagined correlative content could be thought of in very precise terms or in fairly vague terms in different pedagogic contexts. In either case, some recognition of what the learner ought to be like and what their presentation of content ought to entail is always present.

In my exemplification of the central proposition of this article I focus on a specific case of the training of in-service teachers in a Geometer's Sketchpad environment as part of a mathematics education course on the teaching of school geometry, offered as a module on a Bachelor of Science Honours (BSc Hons) programme at a South African university. ${ }^{1}$ Of course, a

1. Written permission to videotape lectures and to audiotape interviews for the purposes of research, and to use those records for analysis and reporting on at conferences and in academic publications, was obtained from the participants in the study. 
serious drawback of case studies is the difficulty of producing generalisable propositions about the phenomena that are perceived to be present. However, the great utility of case studies resides in the opportunities they offer for the production of hypotheses fuelled by the detailed study of the internal relationships and processes found to be inherent to identified phenomena. Such hypotheses then become available for exploration across cases and for larger samples, possibly in transformed states.

The geometry module of concern here made up the first part of a two-module BSc Hons course on geometry and was run over seven four-hour sessions. The students were in-service secondary school teachers who were required to teach some geometry as part of the national school mathematics curriculum. All of the module sessions took place in a computer laboratory, where each teacher had individual access to a computer terminal. The design of the geometry module was underpinned by principles of pedagogic constructivism alongside Van Hiele's theory of the development of geometrical thinking (Van Hiele, 1986) and included the use of Sketchpad environments to develop the dispositions towards mathematics deemed appropriate by the lecturers.

A video recording of each session was produced and made available for analysis in the archive of information on the module. In addition to the video recordings, the archive contained a transcript of an interview with the lecturers of the two modules that made up the course, a course outline for each of the modules, the course material that was handed to students during each session and a copy of a geometry test that teachers sat at the start of the first module. The test was designed to enable the lecturer to read the teachers' responses to the test items in terms of Van Hiele's theory. The test was not referred to by the course lecturers other than in the first session of the first module.

This article is not primarily concerned with either the general problems of pedagogic identity or with the problems of teaching and learning school geometry. What is of primary concern here is the attempted constitution of specific pedagogic identities in pedagogic situations and the attempted alignment of such identities with particular relations of content. More specifically, the pedagogic and discursive mechanisms by which such identity and content constitution and correlation are fashioned are of key interest.

The rest of the article unfolds as three inter-related parts, the first of which explores the construction of the student as lacking, while the second focuses on the elaboration of mathematics content. Part three produces a synthesis of parts one and two, showing how pedagogic identity and mathematics contents are brought together as correlative effects of each other. In each of the distinct parts of the article some additional methodological resources will be required to develop the argument a bit further, but will be introduced as needed rather than spelt out in a separate section.

\section{Part 1: How to be a student of school geometry}

The lecturer for the first module of the course was a mathematics educator who was situated in the education department of the university, while the lecturer for the remaining module was a mathematician from the mathematics department. The mathematics educator saw her task as one of preparing the students to be disposed towards mathematics in a manner that would facilitate their explorations of the mathematics they would encounter in the second module, 'supporting what [Lecturer 2] saw as aims', as she put it during the interview. In her introduction to the course she wrote that her part of the course would 'focus on getting to know Geometer's Sketchpad as a tool to investigate geometrically', as well as giving students the 'opportunity to reflect on the development of spatial knowledge and pedagogy that supports such development'.

The mathematician, who was the more vocal of the two, drew a distinction between learning mathematics as a mere series of techniques for solving various classes of problems and learning something about what mathematics is. 'I have taught for many years and I have students who do well based on learning techniques, but they learn very little', she complained during the interview. 'They learn very little about what mathematics is about, and a lot of people struggle very hard in that learning of very little', she continued, characterising her module as one that would 'allow the students to see things differently, to appreciate things differently and to definitely make connections between diverse things that they never used to connect'. Lecturer 1 explained that she saw the need 'to build in a bit of geometric thinking and geometric development' as the means for realising her goal of supporting Lecturer 2.

In his clarification of Hegel's dialectic, McCumber (1993) developed a number of ideas that prove to be very productive for constructing descriptions of pedagogic exchanges between teachers and their students. While McCumber's purposes are philosophical and so rather different from mine, the descriptive resources he developed are admirably suited to describing the flow of pedagogic discourse. This is, perhaps, not so surprising given that the form taken by the philosophical system developed by Hegel in his Logic (Hegel, 1975) was, in part, a pedagogical solution to having been set the impossible task of preparing a couple of philosophy courses in under two weeks in December 1808 (Pinkard, 2000, p. 322), as well as having to teach students who had no training in philosophy and who had great trouble in engaging with his Phenomenology (Hegel, 1807/1977).

In his re-presentation of the inner workings of Hegel's dialectic, McCumber (1993, pp. 130-43) proposes to achieve his ends by targeting the dynamic 'gestures' inherent to the dialectics of thought. The 'gestures' detailed by McCumber function equally well as resources for describing and analysing the flow of discourse in pedagogic 
situations. Following McCumber, I propose that one way of characterising discourse in a pared-down form is as the gathering together of terms, or groups of terms, that are related to other terms or groups of terms. This may appear to be a rather impoverished reduction of discourse as it unfolds in the interactions between teachers and their students, but the apparatus that emerges around the idea will be seen to be surprisingly productive in capturing the dynamic flow of such exchanges.

Since this discussion is conditioned by Bernstein's theorisation of pedagogy, pedagogic exchanges are to be understood as instances of pedagogic evaluation. Consequently, the elements that I borrow from McCumber will be treated as a set of resources contributing to the operationalising of the description of pedagogic evaluation in pedagogic situations. I will not reference McCumber on every occasion that I use the terms that he uses to construct his description of Hegel's dialectic, but I will italicise my first references to the terms. Recall that my purposes are different from those of McCumber, so that my use of his terms change their meanings from those intended by McCumber somewhat.

I need to introduce a shorthand notation to render the resources concisely. The terms that are referred to shall be referred to as markers and indicated using the notation $M_{i}$ when appropriate. The use of the term 'markers' is appropriate for at least two reasons. Firstly, it corresponds to Hegel's use of the German term merkmal and, secondly, it corresponds to what the French refer to as le trait signifiant, the signifying feature (Žižek, 1994, p. 47). It is especially the latter connection that is methodologically suggestive here because the flow and punctuations of pedagogic discourse are indissolubly bound up with the signifying features that emerge in pedagogic exchanges between teachers and their students, and the discursive punctuations tell us a good deal about the operation of pedagogic evaluation.

An aggregation of markers is indicated by the use of the symbol '. ' positioned between each successive pair of markers, as in: $M_{1} \cdot M_{2} \cdot M_{3}$. Any collection of singular markers, say $M_{j}, M_{k}$ and $M_{l}$, can be aggregated by conjunction to produce $M_{j} \cdot M_{k} \cdot M_{l}$. Given any aggregation, say $M_{1} \cdot M_{2} \cdot M_{3^{\prime}}$ a disjunction may be produced by selecting out one or more terms, as in $M_{3}$ or $M_{1} \cdot M_{2}$ or $M_{1} \cdot M_{3}$ and so forth.

Central to the flow of discourse are the gestures of abbreviation and explication, both of which relate groups of terms. Abbreviation effects a substitution of a group of markers by one or more markers, but always with fewer markers than the original group: $\left(M_{a} \cdot M_{t} \cdot \ldots \cdot M_{r}\right) M_{m}$ indicates that $M_{m}$ abbreviates the aggregate $M_{a} \cdot M_{t} \cdot \ldots M_{r}$. In general, it tends to be the case that abbreviation substitutes a single marker for an aggregate of markers. Explication substitutes an aggregate of markers for a smaller aggregate of markers, or for a single marker: the expression $M_{k} \Leftarrow\left(M_{\sigma} \cdot M_{\eta} \cdot \ldots \cdot M_{\pi}\right)$ indicates that $M_{\sigma} \cdot M_{\eta} \cdot \ldots \cdot M_{\pi}$ is an explication of $M_{k}$. The production of expressions of the type described here should in no way be seen as constituting a calculus with rules of transformation enabling one to move from one expression to the next. The expressions are 'bare bones' symbolisation of features of pedagogic exchanges that could be described in ordinary language. The great utility of the expressions is their ease of use in summarising the features I am interested in, enabling the production of very compact global summaries of general features of entire lectures or lessons. One of the important differences between my use of this notation and McCumber's, which is a consequence of dealing with actual pedagogic exchanges between a lecturer and her students, is that where McCumber uses finite series of marker subscripts that follow the sequence on natural numbers $(1,2, \ldots, n)$, I cannot do so because the temporal unfolding of pedagogic texts is not such that everything pertaining to a particular abbreviation or explication emerges in strict temporal succession. Therefore, while McCumber (1993, p. 132), for example, indicates explication as $M_{n+1} \Leftarrow\left(M_{n-x} \cdot \ldots \cdot M_{n}\right)$, where $n>x$, I use a series of subscripts that do not imply an order (e.g. $\left.M_{k} \Leftarrow\left(M_{\sigma} \cdot M_{\eta} \cdot \ldots \cdot M_{\pi}\right)\right)$ when describing gestures in general terms to avoid suggesting a necessary strict temporal succession of the markers in any expression that is intended to refer to pedagogic exchanges. That said, I do, nevertheless, wish to capture the temporal emergence of markers. To that end, as they emerge, each marker is given a natural number subscript strictly observing the order of the natural numbers, so that the $n$th marker to emerge is given the subscript $n$. When a marker is introduced, by whatever mechanism, the presentation of the marker as the focus for further work is referred to as immediation.

As part of her general strategy for dealing with students' responses, the lecturer would listen to them carefully, repeat what they said in a modified form, but usually seeming to preserve the sense of their statement, and then write down one or more words on the chalkboard to summarise the exchange. In fact, we might interpret the lecturer's strategy as one that effectively produces a series of markers. In the first session of the course, after spending around six minutes on introductions and administrative business, the lecturer kicked off the action by soliciting from her students their associations with school geometry: 'The first question is: if you think of school geometry, what comes to mind? Affective words, content, everything. Anything.'

In different terms, as an opening gambit the lecturer requested an explication of the term geometry from her students. I shall indicate geometry by the marker $M_{1}$, so $M_{1}$ : Geometry is the first marker to be immediated. The students reacted to the lecturer's request by offering the terms listed as follows:
$M_{8}:$ Hard to teach
$M_{6}:$ Reasoning
$M_{3}:$ Theorems
$M_{2}$ : Parallelograms
$M_{9}:$ Hard to learn $M_{7}$ : Diagrams $M_{5}$ : Proofs
$M_{4}:$ Angles
$M_{11}$ : Coordinate geometry

As different students made statements or offered various terms, the lecturer wrote single words or short phrases up on the chalkboard, placing the expressions in different columns, the organising principles of which were not announced. 
Rather than substitute the lecturer's words and phrases with terms of my making, I have chosen to keep her expressions and treat them as markers. The marker indicators alongside each term were, of course, not part of what the lecturer wrote up on the chalkboard and have been inserted here to indicate the sequence in which the students suggested the terms. In each of the figures that I use for the purpose of presenting the terms written up on the chalkboard by the lecturer I will preserve the relative spatial positioning of the terms as far as is possible.

What emerges as an initial explication of $M_{1}$ : Geometry is constructed by treating the students collectively as a communal pedagogic subject, constituting terms from the students' individual offerings and aggregating them as though they derived from a single individual.

The lecturer's particular arrangement of markers in distinct columns, as shown below, indicates an implicit abbreviation of selections of markers, effecting a reorganisation of markers. The lecturer's abbreviations (viz. $M_{12}, M_{13}, M_{14}$ and $\left.M_{16}\right)$ are indicated in bold at the head of each column. A belated offering of a marker by a student, indicated as $M_{15}$ was inserted by the lecturer as she revealed her abbreviations of students' markers and written between $M_{4}$ and $M_{11}$.

$\begin{array}{llll}\boldsymbol{M}_{16}: \text { Affective } & \boldsymbol{M}_{14}: \text { Products } & \boldsymbol{M}_{13}: \text { Processes } & \boldsymbol{M}_{12}: \text { Contents } \\ M_{8}: \text { Hard to teach } & M_{6}: \text { Reasoning } & M_{3}: \text { Theorems } & M_{2}: \text { Parallelograms } \\ M_{9}: \text { Hard to learn } & M_{7}: \text { Diagrams } & M_{5}: \text { Proofs } & M_{4}: \text { Angles } \\ M_{10}: \text { Only clever people } & & & M_{15}: \text { Diagrams given } \\ & & M_{11}: \text { Coordinate geometry }\end{array}$

The production of multiple abbreviations of the students' explications by the lecturer can be viewed retroactively as produced by a series of disjunctions performed on the aggregate $M_{2} \cdot M_{3} \cdot \ldots \cdot M_{11} \cdot M_{15}$ to generate the sub-aggregates $M_{2} \cdot M_{4} \cdot M_{11} \cdot M_{15}, M_{3} \cdot M_{5}, M_{6} \cdot M_{7}$ and $M_{8} \cdot M_{9} \cdot M_{10}$. The sub-aggregates are regulated by the implicit markers $M_{12}$ : Contents, $M_{13}$ : Processes, $M_{14}:$ Products and $M_{16}:$ Affective as they are used to effect the abbreviations $\left(M_{2} \cdot M_{4} \cdot M_{11} \cdot M_{15}\right) \Rightarrow M_{12^{\prime}}$ $\left(M_{3} \cdot M_{5}\right) \Rightarrow M_{13^{\prime}}\left(M_{6} \cdot M_{7}\right) \Rightarrow M_{14}$ and $\left(M_{8} \cdot M_{9} \cdot M_{10}\right) \Rightarrow M_{16}$.

A fundamental purpose of the use of the series of abbreviations by the lecturer is revealed to be one concerned with generating material that enables her to focus attention on the affective. She performed a disjunction on the aggregate of category markers, $M_{12} \cdot M_{13} \cdot M_{14} \cdot M_{16}$, selecting out $M_{16}$ for further elaboration:

L: And here you have some affective factors. Can anybody say something positive about geometry?

Ss: [Laughter]

L: What was positive? What can you think of as positive from geometry? Your experience of geometry.

A student offered a few suggestions that are included under the category of the affective by the lecturer, extending the explication of $M_{16}:$ Affective to include $M_{17}$ : Can reason things out and $M_{18}$ : Learning.

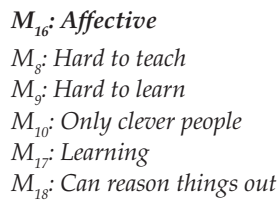

Before moving on, this is an appropriate point at which to introduce a couple of McCumber's gestures: reflection and counter-reflection. McCumber (1993, p. 132) stipulates that markers that have been conjoined by both $\Rightarrow$ and $\Leftarrow$ are to be considered as having been caught up in the transition to reflection, for which he uses the connective $\Uparrow$. McCumber's point appears to be that the movement from abbreviation to explication for a given marker has the effect of shifting attention to reflection because it gives us pause: subsequent to abbreviation and explication we are caught in a situation that has us move from 'something done to something thought about' (p. 134; italics in the original). As an example, consider $M_{16}$. Having introduced $M_{16}:$ Affective as an abbreviation of the aggregate $M_{8} \cdot M_{9} \cdot M_{10^{\prime}}$ viz., $\left(M_{8} \cdot M_{9} \cdot M_{10}\right) \Rightarrow M_{16^{\prime}}$ the immediate additional attention given to $M_{16}$ entailed a further explication of $M_{16}$, viz., $M_{16} \Leftarrow\left(M_{17} \cdot M_{18}\right)$, which has the consequence of generating $M_{16} \Leftarrow\left(M_{8} \cdot M_{9} \cdot M_{10} \cdot M_{17} \cdot M_{18}\right)$ as a fuller explication. Considering $M_{16}$ as an abbreviation now, we have $\left(M_{8} \cdot M_{9} \cdot M_{10} \cdot M_{17} \cdot M_{18}\right) \Rightarrow M_{16}$.

We thus have two ways of reading $M_{16}$. First, as an abbreviation: the properties marked by $M_{8^{\prime}}, M_{9^{\prime}} M_{10^{\prime}} M_{17}$ and $M_{18}$ are collectively to be called 'affective'. Next, as the subject of a series of explications: 'affective' has the series of effective properties marked by $M_{8}, M_{9}, M_{10}, M_{17}$ and $M_{18}$. Stated in this way, as though $M_{8^{\prime}} M_{9}, M_{10^{\prime}} M_{17}$ and $M_{18}$ were necessary properties of $M_{16}$, we immediately feel the conceptual strain of encountering the contingent (i.e. $M_{8}, M_{9}, M_{10}, M_{17}$ and $M_{18}$ ) appearing in the guise of the necessary. The impossibility thus produced forces on us the gesture of reflection: 'something thought about'.

To indicate that we are dealing with an abbreviation or explication of $M_{16}$ under the aspect of reflection, we write $\left(M_{8} \Uparrow M_{9} \Uparrow M_{10} \Uparrow M_{17} \Uparrow M_{18}\right) \Rightarrow M_{16}$ to represent abbreviation and $M_{16} \Leftarrow\left(M_{8} \Uparrow M_{9} \Uparrow M_{10} \Uparrow M_{17} \Uparrow M_{18}\right)$ to represent explication, from which we can write $\left(M_{8} \Uparrow M_{9} \Uparrow M_{10} \Uparrow M_{17} \Uparrow M_{18}\right) \Uparrow M_{16}$ as representing reflection, tout court.

The important Hegelian point is that, in general, the precipitation of an impossibility out of the construction of a coincidence of abbreviation and explication engenders the gesture of reflection.

To symbolise counter-reflection McCumber stipulates that an expression indicating reflection, like $\left(M_{8} \Uparrow M_{9} \Uparrow M_{10} \Uparrow M_{17} \Uparrow M_{18}\right) \Uparrow M_{16}$, permits us to write the aggregate $\left[\left(M_{8} \Uparrow M_{9} \Uparrow M_{10} \Uparrow M_{17} \Uparrow M_{18}\right) \Rightarrow M_{16}\right] \cdot\left[M_{16} \Leftarrow\left(M_{8} \Uparrow M_{9} \Uparrow M_{10} \Uparrow M_{17} \Uparrow M_{18}\right)\right]$ from which we are free to focus on either of the more complex markers or their constituents.

The lecturer quizzed a student on the teaching of geometry, using his responses to focus in on an explication of $M_{9}$ : Hard to learn. 
$\mathrm{L}: \mathrm{Mm}, \mathrm{mm}$. And teaching geometry?

S: Teaching geometry. That is what the kids have a problem with doing. They ... In other words, that they prefer you having something that's already mapped out for you. In other words, you start at a point and you end. And the steps in-between they know how to get there. But geometry is a little bit more ... You have to search. You have to play around with things. And extract from what you're given. You have to extract the solution.

L: Do you think that's what makes it hard for them?

As the students responded to the lecturer's question she listed their responses in a manner that amounts to explications of both $M_{8}$ and $M_{9}$. The linking of the student's response to $M_{9}$ : Hard to learn effects a disjunction on the aggregate $M_{8} \cdot M_{9} \cdot M_{10} \cdot M_{17} \cdot M_{18}$, resulting in an immediation on $M_{9}$. The lecturer focused briefly on getting the students to explicate $M_{8}$ : Hard to teach in a similar fashion, once again using disjunction on $M_{8} \cdot M_{9} \cdot M_{10} \cdot M_{17} \cdot M_{18}$ (to immediate $M_{8}$ ), but then shifted the emphasis to explicating $M_{9}$ : Hard to learn, producing a fairly extended series of explications. As usual, the indexes of markers indicate the order in which they emerged and the spatial positioning of the markers indicates their locations relative to other markers.

$\begin{array}{ll}M_{8}: \text { Hard to teach } & M_{9}: \text { Hard to learn } \\ M_{21}: \text { Foundations not in place } & M_{20}: \text { Open-ended, creativity needed, needs problem- } \\ M_{23}: \text { Textbook bound } & M_{25}: \text { Visualisation: reading of diagrams } \\ & M_{27}: \text { No practical link } \\ & M_{28}: \text { Not important, for example, for commerce } \\ & M_{19}: \text { Manoeuvre: search to get to the endpoint of a } \\ \text { problem } & M_{26}: \text { Apply what is learnt } \\ & M_{22}: \text { Perception: only clever people } \\ & M_{24}: \text { Children required to work above their } \\ & \text { developmental level }\end{array}$

The lecturer brought the explications of $M_{8}$ and $M_{9}$ to a close and then effected a disjunction on the aggregate $\left(M_{21} \cdot M_{23}\right)$ to select out and immediate $M_{21}$ : Foundations not in place.

L: Lots of interesting things that you bring up here. The first that I want to explore with you further, you said they find it difficult because the foundation is not in place, because in the lower grades they were textbook bound. What would you say is a proper foundation for geometry at the levels at which you teach it, which I take is high school level? Right? What do you see as a proper foundation? What would you want?

As she spoke she cleared a section of the chalkboard and wrote the heading 'Foundation', effectively generating a new marker off $M_{21}$ : Foundations not in place, which I shall refer to as $M_{29}$ : Foundation. This move is one that contracts $M_{21}$ to produce a form that the lecturer deems to be more appropriate to the further development of her teaching. McCumber does not have a term for such a gesture, so I'll name it contraction, and we can say that the lecturer performed a contraction on the marker $M_{21}$ : Foundations not in place to produce the marker $M_{29}$ : Foundation. In addition, I use the symbol $\subset$ as a connective to indicate contraction, as in $M_{29} \subset M_{21}$. The students generated a series of explications in response to $M_{29}$ : Foundation:
$M_{29}:$ Foundation
$M_{30}:$ Practical exploration
$M_{31}$ : Measurement
$M_{32}$ : Introduce geometry in the same way as it developed historically
$M_{33}$ : Basic axioms
$M_{34}:$ Use and understanding measurement instruments. Length vs size of angle. Units (Vocabulary: big os long)

The lecturer then effected a disjunction on $\left(M_{20} \cdot M_{25} \cdot M_{27} \cdot M_{28} \cdot M_{19} \cdot M_{26} \cdot M_{22} \cdot M_{24}\right)$, immediating $M_{24}:$ Children required to work above their developmental level.

L: The other thing I want to pick up with you is ... children are asked to work above their developmental level. How do we gauge their developmental level? What gives you an idea that they are not ready for it and at another time, when? What are the characteristics of that readiness from your experience? Say we think of a Grade 8 learner coming in to your class, and you need to do geometry with them. What is it, typically, that you find they can't do, which you think they are just not ready for?

The lecturer's questioning of the students implicitly effected a contraction to produce the marker $M_{35}$ : Developmental level from $M_{24}$ (i.e., $M_{35} \subset M_{24}$ ), with $M_{35}$ becoming the object of explication, the result of which is $M_{35} \Leftarrow\left(M_{36} \cdot M_{37}\right)$.

\section{$M_{35}:$ Developmental level \\ $M_{36}$ : Statement/reason; given/asked \\ $M_{37}$ : link together $\rightarrow$ build a logical argument}

With $M_{29}$ and $M_{35}$ the discussion is seen to home in on a pair of twin lacks, one of which is associated with teaching and the other with learning. The message is that teaching is responsible for setting in place adequate foundations for students to be working at an appropriate developmental level, but that both teaching and students are lacking.

It is at this point that the lecturer introduced a shift from the realm of opinion and experience to knowledge as it is realised in theory, by asking the students to redescribe the lack in school students in theoretical terms.

L: I'm sure that you've done some learning theory. Things like that. Last year and this year. Have you? Can you link any of that knowledge, of theories of learning, of theories of development, to this thing of 'they are not ready'?

The students were not all that forthcoming on the matter, but that was not an issue for the lecturer because her aim had been to set in place the conditions for her to insert the Van Hiele theory of the development of geometrical thinking, thus producing a relation that functioned like an abbreviation, viz., $\left(\left(M_{36} \cdot M_{37}\right) \cdot\left(M_{30} \cdot M_{31} \cdot M_{32} \cdot M_{33} \cdot M_{34}\right)\right) \Rightarrow$ van Hiele.

By means of using what students would have experienced as a record of their own thoughts on school geometry, they had been taken from their experiences to a point where they would have to confront themselves as lacking with respect to both pedagogy and mathematics. Van Hiele testing was presented as a benign, scientific measure of the state of geometrical thinking, as the lecturer attempted to downplay the element of lack: 
L: What we are going to do now ties in with developmental levels. I'm going to give each of you a copy of the Van Hiele geometry test, or assessment instrument. Now, this instrument is used all over the world for in-service teachers and for children at all kinds of levels to ascertain their geometric thought levels. So this is not something you can fail or pass. It simply throws out a level of thinking, and we're going to work with this Van Hiele level of geometric thinking a lot. We're going to relate what we do on Sketchpad back to this. We're going to try and ascertain our own levels of thinking. We are going to become aware of where we are aiming to get to and what the characteristics are of a level we need to be on to understand our school geometry.

Twenty-eight minutes into the lecture the lecturer handed out what she referred to as a Van Hiele test for students to work on individually. She collected their answer sheets and the test booklets about 36 minutes later. After the students had a break, the lecturer assured them that the developmental levels revealed by a Van Hiele test are not age dependent but related to previous experience:

L: Interestingly enough, I've worked a lot in adult education, and we find the exact same developmental path, from young, young children-I'm talking from three years and on-or with adults that haven't been schooled before. So it seems to be an inherent development of geometrical thought that's not so much dependent on age, but on what came before. Okay?

At this point it would be helpful to present an overview of the flow of the pedagogic exchanges between the lecturer and her students. Figure 1 shows a network representing the flow of explications and abbreviations that emerged during the lecture. Starting from an invitation to students to explicate geometry, the pedagogic exchanges are regulated by the lecturer, who uses carefully selected disjunctions to steer the discussion in the direction of explications of the affective, from which she finds material enabling her to pick up on teaching and learning with respect to failure, thereby registering the existence of a pair of lacks that are to be unified by considering them in relation to the Van Hiele theory of the development of geometrical thinking.

In slightly different (Hegelian) terms, we see that the lecture unfolds by starting with the actuality of the phenomenal experience of the students and then focuses in on affective issues, and it is only in relation to the affective that we see the formal structure of reflection emerging in the pedagogic exchanges, and precisely around the twin issues of a lack in teaching and a lack in learning. While the references to the lacks in teaching and learning connect deeply with teachers' experiences, this is also the moment when the actuality of their immediate experiences is suspended by the production of the twin contractions that immediate the markers of Foundation and Developmental level, $M_{29}$ and $M_{35}$. What these might be pushes pedagogic discourse to confront the openness of possibility, which is exactly what reflection generates. The introduction of the Van Hiele test and the appeal to that theory of the development of geometrical thought closes down the openness and inserts a new necessity into the discourse, where Van Hiele is intended to describe and explain everything-successes and failures.

The lecturer's general pedagogic strategy of inviting her students to offer explications of various terms means that she constantly has to deal with the contingent: she cannot know in advance what will emerge from her students' responses. We have also seen that she uses disjunctions and explications very skilfully to keep the discourse flowing in the general direction that she prefers. What this tells us is (1) that the contingent emerges at each of the moments of actuality, possibility and necessity in the discursive flow and

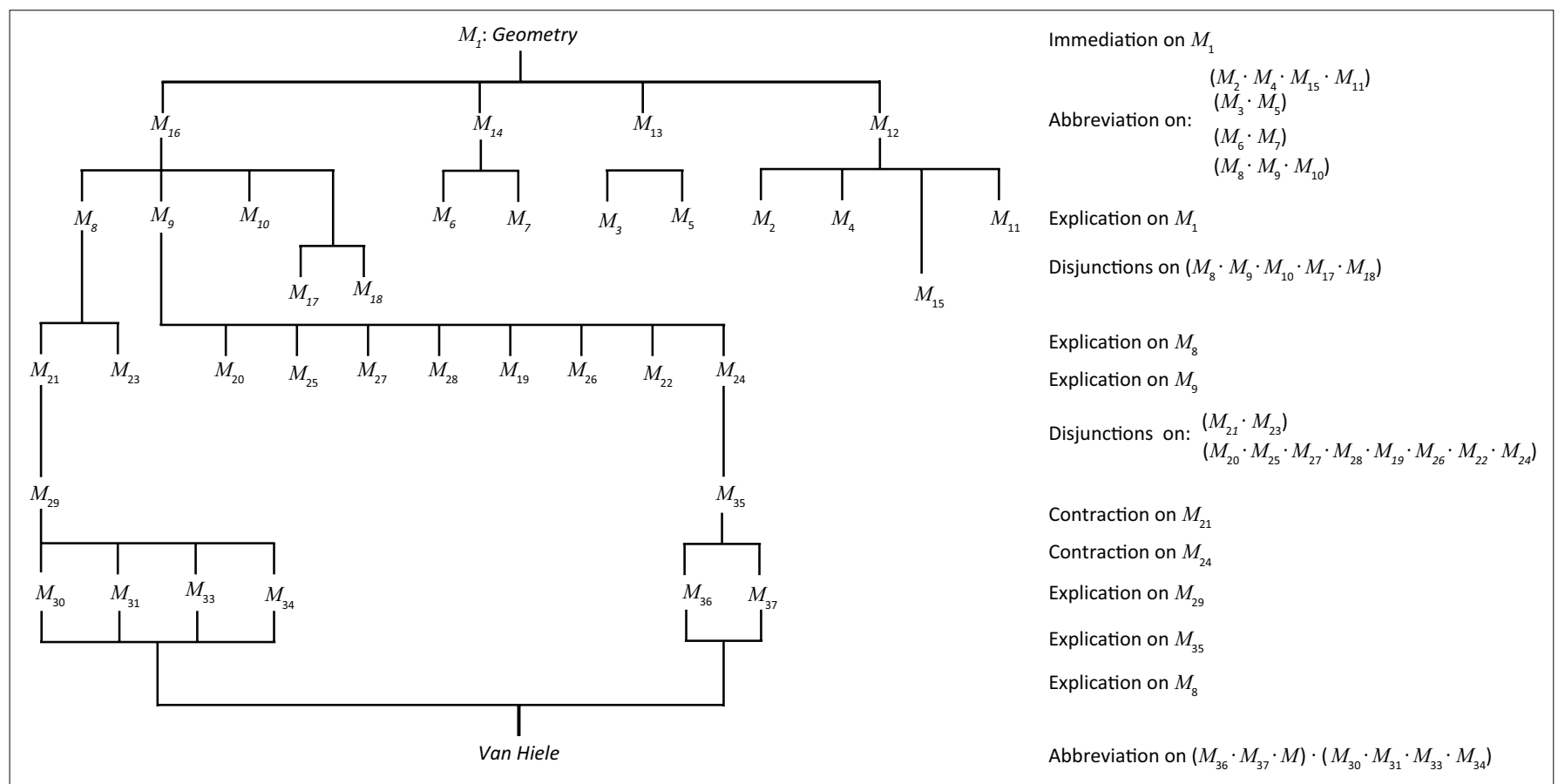

FIGURE 1: Network showing the flow of abbreviations and explications from $M_{1}$ to the insertion of Van Hiele. 
(2) that the lecturer's disjunctions, abbreviations and invitations to explicate are constituents of pedagogic evaluation.

As already mentioned, the flow of pedagogic exchanges produces two inter-related splits, one internal to knowledge, the other internal to the pedagogic subject. The former is registered in the indirectly voiced distinction between knowledge deriving from pedagogic experience versus knowledge deriving from the Van Hiele theory (opinion versus knowledge, in Platonic terms), the latter in the distinction between the pedagogic subject's imagined geometrical skill (as registered in grade level, for example) versus their determined Van Hiele level. So, by the conclusion of the first session of the course, the students had been taken from the certainty of their phenomenal experiences as teachers of geometry to the point of encountering themselves as lacking in both knowledge of geometry as well as in the teaching of geometry, thus setting the stage for their engagement with geometry in the sessions to follow.

\section{Part 2: How to draw a square}

The Sketchpad environment is, amongst other things, an environment that exploits the visual representation of mathematical content as a central resource for the teaching and learning of school mathematics. Each of the students had a personal copy of Sketchpad, including a manual and a copy of the Geometer's Sketchpad Learning Guide (GSLG; Chanan, 2001) and each had access to their own computer workstation in the computer laboratory used for the duration of the module. At the start of Session 2 the lecturer drew the students' attention to a task in the GSLG that required them to construct a square:

L: Now you will see on page sixteen constructing a square is the task there. My purpose for taking you to this task is, apart from what you will learn in the outcomes that they have there. I talk you through this thing. Say do this, do this, do this. And you will always be dependent on me. Right? I want you to follow the text and try out, following the text, what they want you to do. It will take you, I think, around about half an hour to come up with a constructed sketch of the square, and after that we're going to discuss why it had to be along these lines.

The problem of constructing a square in the task on page 16 of the GSLG is explicitly used as a vehicle for introducing the Sketchpad neophyte to the commands and functions available in the Sketchpad environment.

The students responded to the task in three different ways. Firstly, there were those who attempted to produce a foursided figure that looked more or less like a square and then proceeded to drag the vertices of their drawings to produce an approximation to a square. The images in Figure 2 show the work of two such students. Next were the students who produced squares by measuring the lengths of the sides and the angles between adjacent sides of the quadrilaterals they drew. Such students used the lengths and angle measures to adjust their quadrilaterals so that the definition of a square was satisfied. A third group of students followed the instructions

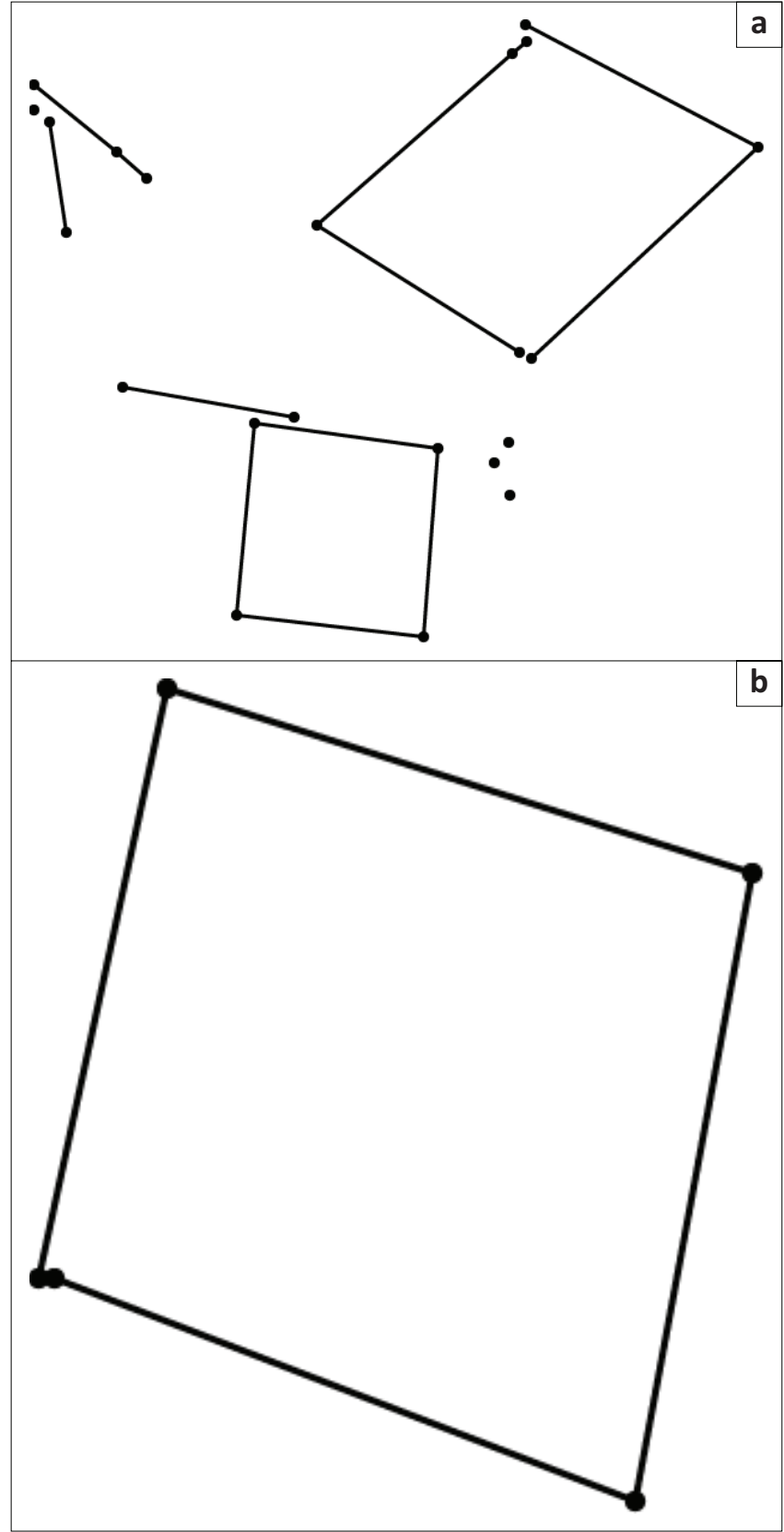

FIGURE 2: Attempted imagistic approximations to a square.

listed in the GSLG and were able to produce the constructions as illustrated in the text (see Figure 3 for an example). We shall refer to the three methods used to produce a square as Method 1, Method 2 and Method 3, respectively.

Method 1 shows an attempt at using pictorial similarity as the chief resource for producing a square: if it looks like a square then it is a square. The students using Method 1 would, of course, have to know something about what a square looks like and so would more than likely know something about the definition of a square. However, it is the image of the square that appears to be primary for such students, so that the formal definition of the square functions as a description of the image and is therefore secondary to that image. In other words, what can be seen enjoys a much more substantial reality that that which is discursively rendered. 


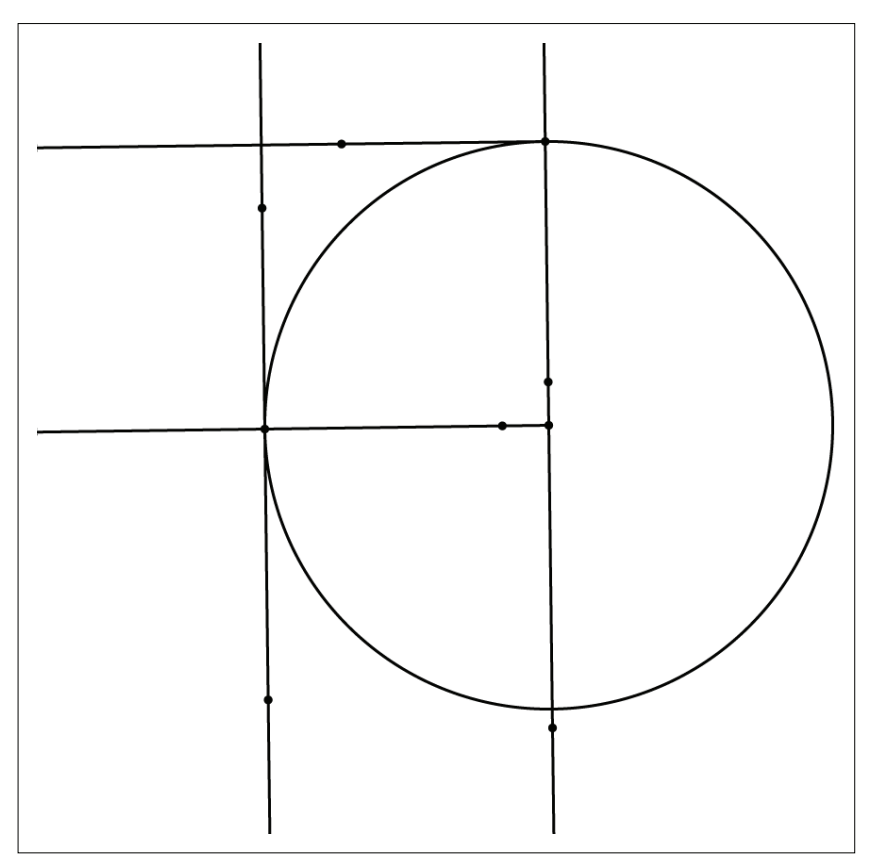

FIGURE 3: Attempt at the construction of a square as illustrated in the GSLG.

The students employing Method 2 use the definition of a square, so that the image of the square is a representation of a square as discursively defined. Here the definition of the square is central to the reality of what a square is. However, the students using this method imagine that accurate empirical measurement is required to realise a square, so that empirical measure is central to the realisation of the square.

Method 3 enables the students to produce a construction that is more stable than that generated by Method 2. A square produced by Method 3 is not destroyed by dragging any of its vertices, unlike one produced using Method 2. Method 3 is, in a sense, indifferent to empirical measure in that the square is, in the first instance, produced by fixing its elements in a system of formally defined determining relations. Here the particular empirical measures of angles and sides of any square so produced are effects of the formally defined relations between sides and angles. Further, the image of the square, that is, what a square looks like, is also an effect of those formally defined relations.

The different emphases of the three methods discussed above can be read as co-present in particular instances of the production of a square. For example, the student using Method 2 starts by drawing a roughly square-like quadrilateral (image) and then adjusts the positions of its vertices by using measures of angles and lines (empirical measure) so that the relations between the angles and lines conform to the formal definition of a square (definition). Similarly, we would expect that the student starting from formally defined relations (definition) as in Method 3 checks that the square they produced looked like a square (image) and that they might even measure angles or lengths (empirical measure) if the image suggests that a quadrilateral other than a square has been produced. At the very least, the students using Method 1 appear to appeal to a proto-definition of a square: the software forces them to select and draw the four vertices and four line segments (definition) that are needed to be arranged in a particular configuration that is visually recognisable as square-like (image), the latter requiring some sense of measure to realise (empirical measure).

What is of interest is that three methods show three different emphases. Method 1 is dominated by the image, Method 2 by empirical measure and Method 3 by formally defined relations. This statement needs to be understood by focusing on what the primary resource is and what is secondary in regulating the activity of producing a square in each of the methods, where what is secondary is positioned as an effect of that which is primary. Central to each method is a particular type of regulation of mathematical activity and corresponding to each regulative type we have a primary means for evaluating the existence of the square that can be framed in the form of a series of questions: (1) Does it look like a square? (2) Are its sides of equal length and each of its angles 90 degrees? (3) Does its construction satisfy the formal relations entailed in the definition of a square? As before, in each of the three questions we can hear the echo of the other questions, but what is important to attend to is the determination of what I shall refer to as a regulative orientation, indexed by taking a particular question as primary.

A regulative orientation can be understood as colouring the student's mathematical activity in a particular way, producing an over-determining effect on that activity. We might describe the primary regulation of the mathematical activity of the student in more general terms as exhibiting iconic, empirical or formal orientations. Describing the activity of students in general terms permits us to describe empirical instances of mathematical activity beyond the case under consideration here. To that end, we need to express the primary and secondary resources that figure in regulative orientations in general terms as well. There are three general types of resources: images, empirical tests and formally defined relations between mathematical objects. In the particular instance discussed here, the empirical test was one of measuring angles and lengths, but empirical tests can take many different forms. School learners, for example, are often asked to check the validity of their algebraic transformations of expressions by substituting actual numbers for the variables or unknowns, or teachers might substitute numbers into expressions in an attempt to convince learners of the validity of a statement.

Now it might be argued with some justification that an appeal to an image is also a sort of empirical test-and I would agree. An important difference between the appeal to an image and measuring or substituting numbers into expressions is that the former entails a very weak form of validity, usually requiring more stable empirical testing or appealing to formal definitions or propositions to convince oneself and others of the truth of a claim grounded in the iconic. In fact, as concerns the mathematical validity of claims, it is apparently the case that the claims generated 
from the different regulative orientations can be arranged in a hierarchical sequence starting from the mathematically least valid: firstly, claims grounded in the iconic, then those that are empirically grounded and, finally, those grounded formally. This is not to deny that pedagogic experience has often shown us that formally grounded claims might well be the least convincing to the school mathematics student.

Table 1 summarises significant features of the analytical language developed from a consideration of Session 2 of the geometry module to this point. I shall now return to Session 2 to develop the discussion a bit further.

\section{Drawing versus construction}

Once most of the students managed to produce the square as required by the GSLG task, the lecturer marked out the differences between what she referred to as drawing and construction:

L: When we started out you made some drawings with those tools. Right? You can draw a circle; you can draw a line; you can draw a square with the lines. Do you agree? What makes those drawings different from the construction of the square that you did? What's the difference between just taking the line and drawing the square to the construction of the square?

S: I suppose that when you're drawing the square you start moving the points and it does not necessarily stay a square. But when it's constructed and you start moving the points around it will remain a square, no matter what angle you rotate it through, and no matter how close you bring the points, or how far apart they are.

L: Did you observe that? If you just draw a square, then you can even mark the points, or whatever. If you just draw, the thing remains free. Right? You can move those lines into any other configuration that you want to, which remains free. It isn't defined as a square. It just looks like a square. With me ... Whereas, when you constructed the square, you sat with a defined object, which you could manipulate on the screen. You could take any of the points and move it around. Yes, it shrunk, or, you dilated it. Or, you can turn it, but if you watch the measurements, you still let your angle remain ninety degrees, and however the side lengths change, they remain equal to each other. Do you agree?

The lecturer, following the GSLG, set drawing and construction in opposition. She associated drawing with the simple reproduction of images of geometrical objects and construction with the formal definitions of those objects. For the lecturer, drawing was grounded in the iconic and construction in the formal. The GSLG refers to a particular test to be used to check whether or not a geometrical object was produced by straight-edge and compass construction, viz., the drag test.

TABLE 1: Summary of analytical terms and their relations.

\begin{tabular}{lll}
\hline Regulative orientation & Primary resource & Secondary resources \\
\hline Iconic & Imagistic similarities & $\begin{array}{l}\text { Empirical tests/ } \\
\text { Propositional relations }\end{array}$ \\
Empirical & Empirical tests & $\begin{array}{l}\text { Imagistic similarities/ } \\
\text { Propositional relations }\end{array}$ \\
Formal & Formal relations` & $\begin{array}{l}\text { Imagistic similarities/ } \\
\text { Empirical tests }\end{array}$ \\
\hline
\end{tabular}

As its name suggests, the test requires the student to drag some element of a figure, usually a point, to check whether the figure is stable. If the figure does remain stable, then the student can assume that the relations between its constitutive elements remain true to the formal definition of the particular geometrical the figure it depicts. If, for example, the square was not produced by the equivalent of straight-edge and compass construction, then the relations between its sides and angles would be altered by the drag test, destroying the square (see Figure 3). So, even if a square is produced in strict accordance with its definition, but not by straight-edge and compass construction, it is fated to be destroyed by the drag test. Within the Sketchpad environment the strong distinction being made in this particular instance is between geometrical objects produced by Euclidean methods and those not so produced. For the lecturer, the use of the formal definition of objects is associated only with 'construction'. Over the seven lectures that make up the module, the lecturer used a number of oppositions that she saw as related to the drawingconstruction opposition: spatial thought vs geometric thought, free vs defined, and remembering vs visualising.

The drawing-construction opposition (see Figure 4) used by the lecturer (and the GSLG) also suggests related descriptive categories other than drawing and construction, but which remain hidden in the lecturer's interaction with her students. We can define two descriptive categories that are neither drawing nor construction by considering the contradictories of construction and drawing in relation to the opposition drawingconstruction: firstly, we have a class of squares that are reasonably accurate representations of squares within the Sketchpad environment, obtained by means of empirical testing, but which collapse when subjected to the drag test; secondly, there is also a class of objects intended as squares but which do not even look like squares (see Figure 2 for an example).

By using the semiotic schema proposed by Greimas (1968), which he derived from the Aristotelian square of oppositions, I can expand the lecturer's descriptive schema from a simple opposition to a more complex schema of four inter-related categories, a first rendition of which is shown in Figure 5. The categories are drawing, construction, notdrawing and not-construction, where drawing vs construction is the primary opposition of contraries as constituted by the GSLG and the lecturer. The oppositions drawing vs notdrawing and construction vs not-construction are oppositions of contradictories derived from the primary contrary opposition. The opposition not-construction vs not-drawing is also one of contrariness and those categories entail the sub-contraries. The relations between drawing and notconstruction on the one hand and construction and notdrawing on the other are relations of entailment: drawing is entailed in the category of not-construction and construction in that of not-drawing.

I can now describe the categories derived from the drawingconstruction opposition in terms of the categories of regulative orientation developed earlier (refer to Table 1). 


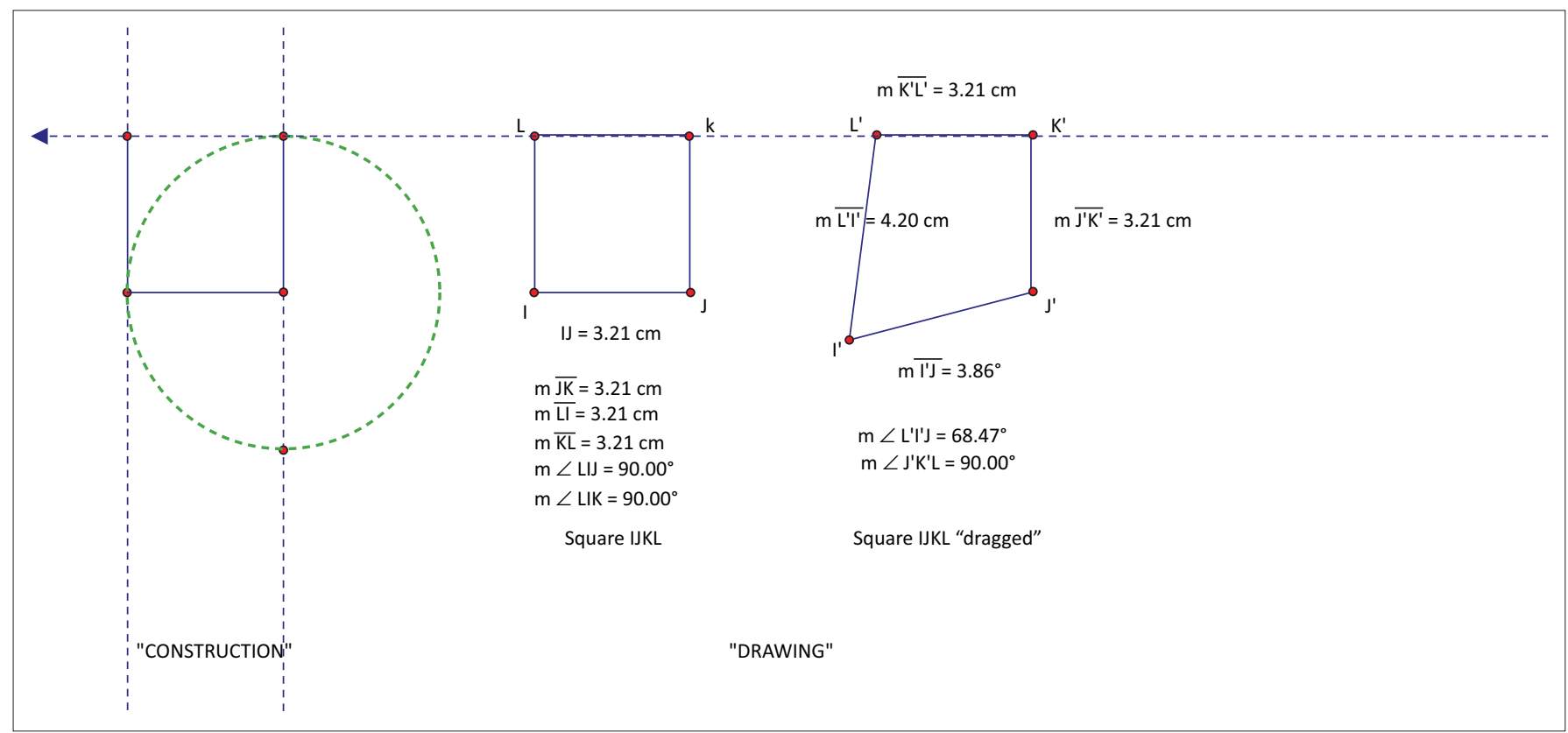

FIGURE 4: 'Drawing' vs. 'construction' of a square in Sketchpad.

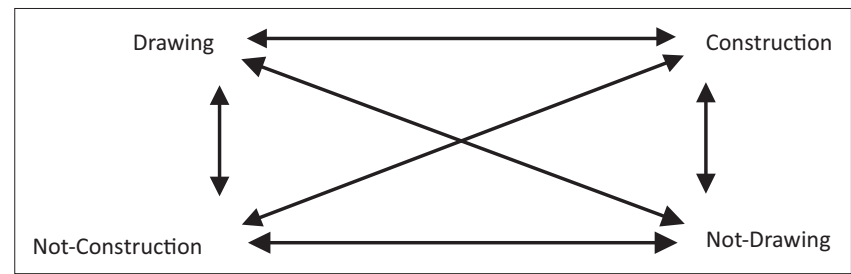

FIGURE 5: Greimassian semiotic square derived from the drawing-construction opposition.

In the context of the Sketchpad environment, what are considered drawings as opposed to constructions are those sketches produced under iconic and empirical regulative orientations. The empirical orientation is one that entails a degree of iconicity, which suggests that not-construction be associated with an iconic regulative orientation and drawing with an empirical regulative orientation.

Further reflection on the category not-drawing suggests that the categories of regulative orientation need to be rethought. One the one hand, not-drawing corresponds to objects that are produced with, at best, a partial description of the object in mind. Within the expanded schema it might be interpreted as the only category that does not appeal to a definition adequate to the purpose of producing an image of a square. On the other hand, as all mathematics teachers are aware, there exist notational resources, like particular symbols for indicating right angles and equal lengths, that can be attached to any suitable rough sketch to mark it as a square, an example of which is shown in Figure 6.

The class of such squares would not function as legitimate responses to the demands of the task in this instance: such a representation of a square is really functioning as a pictorial description, in much the same way as a definition presented in written or spoken language, rather than a Euclidean construction of a square.
Given that construction has to be understood as entailed in not-drawing, and thinking about a formal regulative orientation as constituted by both algorithmic and propositional orientations, with the former entailed in the latter, construction can be associated with an algorithmic regulative orientation and not-drawing with a propositional regulative orientation. Such an arrangement makes good sense since the construction of the square emerges from the constitution of an appropriate method that is derived from Euclidean propositions and relations between them. What has thus been produced, summarised in Table 2, is a revision of the regulative orientations that were presented in Table 1.

The diagram of the semiotic square derived from the drawingconstruction opposition can now be elaborated a bit further by mapping the revised regulative orientation categories on to the series drawing, construction, not-construction, not-drawing, as in Figure 7.

The iconic and propositional regulative orientations, which now stand in opposition by being associated with the subcontrary opposition not-construction vs not-drawing, bring the latter opposition under the aspect of the sensible-intelligible and opinion-knowledge oppositions central to the Platonic universe.

\section{Part 3: A square in drag as concrete universal}

The manner in which the lecturer uses the drawing-construction opposition reveals something interesting about the position of the empirical in the privileged pedagogy of the module. Recall that the lecturer asserted the following in support of construction:

When you constructed the square, you sat with a defined object, which you could manipulate on the screen. You could take any of 
the points and move it around. Yes, it shrunk, or, you dilated it. Or, you can turn it, but if you watch the measurements, you still let your angle remain ninety degrees, and however the side lengths change, they remain equal to each other. (my emphasis)

The straight-edge and compass construction of the square demonstrated in the GSLG determines the square as such, so that the construction is itself the proof that the figure is indeed a square. The lecturer and her students, however, never used the construction to prove that the figure they constructed was a square. Instead, they used measure as an empirical test of the truth of the square as square. Even in her discussions with individual students the lecturer repeatedly called for and encouraged them to perform empirical tests using measure to check their constructions. We see that, on the one hand, squares produced by empirical testing fail the drag test and are thereby marked as non-legitimate constructions; on the other hand, empirical testing is considered sufficient to validate the equivalent of a straightedge and compass construction of the square. In other words, empirical testing comes to be aligned with both drawing and construction and, in that way, with both the individual and the universal. It would therefore appear that an empirical orientation is used in an attempt to assert the universal and that we have a so-called inductive pedagogy in play. In her written introduction to the course the lecturer had informed students that they would 'get opportunities to engage in

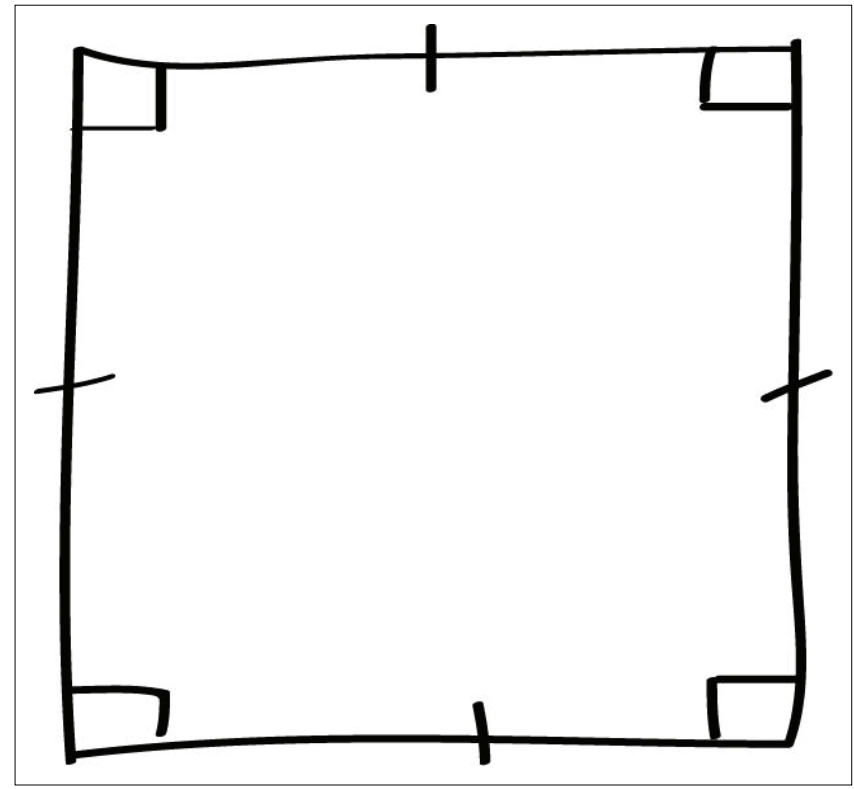

FIGURE 6: A pictorial description of a square.

TABLE 2: Summary of revised analytical terms and their relations.

\begin{tabular}{lll}
\hline Regulative orientation & Primary resource & Secondary resources \\
\hline Empirical & Empirical tests & $\begin{array}{l}\text { Imagistic similarities/ } \\
\text { Propositional relations/ } \\
\text { Algorithms }\end{array}$ \\
Algorithmic & Algorithms & $\begin{array}{l}\text { Imagistic similarities/ } \\
\text { Empirical tests/ } \\
\text { Propositional relations }\end{array}$ \\
Iconic & Imagistic similarities & $\begin{array}{l}\text { Empirical tests/ } \\
\text { Propositional relations/ } \\
\text { Algorithms }\end{array}$ \\
Propositional & Propositional relations & $\begin{array}{l}\text { Imagistic similarities/ } \\
\text { Empirical tests/Algorithms }\end{array}$ \\
\hline
\end{tabular}

hypothesising, testing by experiment and proving in the context of synthetic geometry; transformations and analytic geometry', but there was very little evidence of students engaging with proof over the seven sessions.

What the session reveals is the general structure of the inductive pedagogies widely championed in the preparation of teachers for the teaching of school mathematics today. The structuring matrix of the pedagogy is of the form particularsingular-universal, where the particular is given as a particular task and the singular is constituted by the contingent activity of the student. That is, students are confronted with some particular situation from which a problem emerges (construct a square) and in response to which a series consisting of singular student reactions is produced (individual squares) to mediate between the particular and the universal (squareas-such). Here an attempt is made at effecting a shift from the particular to the universal by establishing a pair of links of the form: particular-singular/singular-universal.

\section{Hegel (1816/1969, p. 690) describes induction as}

the syllogism of experience-of the subjective taking together of the individuals into the genus and of the conjoining of the genus with a universal determinateness because this latter is found in all the individuals. (italics in the original)

Hegel does, however, warn of the problems of proceeding inductively as he sets about describing the central features of induction, from which we can recognise that mathematics as we know it could not have been generated inductively. That is, mathematical systems would collapse if they were constructed solely on series of inductive conclusions that remain problematical.

[Induction] is ... essentially a subjective syllogism. The middle terms are the individuals in their immediacy; the subjective taking together of them into the genus by means of allness is an external reflection. On account of the persistent immediacy of the individuals and their consequent externality, the universality is only completeness, or rather remains a problem. In induction, therefore, the progress into the spurious infinite once more makes its appearance; individuality is supposed to be posited as identical with universality, but since the individuals are no less posited as immediate, that unity remains only a perennial ought-to-be; it is a unity of likeness; those which are supposed to be identical are, at the same time, supposed not to be so. It is only when the $a, b, c, d, e$ are carried on to infinity that they constitute the genus and give the completed experience. The conclusion of induction thus remains problematical. (Hegel, 1816/1969, pp. 690-691; italics in the original)

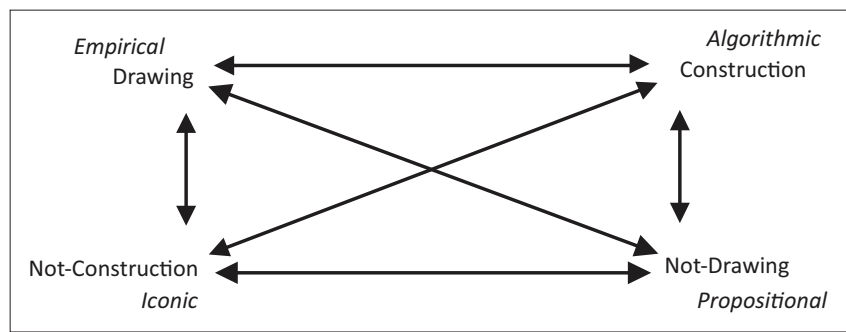

FIGURE 7: Revised regulative orientations mapped onto the constructiondrawing opposition. 
We should note that the pedagogic modality privileged by the lecturer is only apparently inductive. Firstly, and most obviously, the pedagogic modality has as its object the reproduction of mathematics, not the production of new mathematics. This is not to deny that the student might experience the reproduced mathematics as new. Secondly, the organisation of the pedagogic text is such that the tasks the student is confronted with already have encoded into them, in a condensed form, the conceptual work that went into the production of the mathematics content. That is, tasks are always-already structured from the position of knowledge of the content that is to be acquired. Thirdly, it follows that the aforementioned structuring of tasks provides an implicit guarantee that the finally arrived at content will indeed be legitimate mathematics content.

In other words, an elaborate game is being played in which the student agrees to proceed as though they are a producer of mathematical knowledge who employs inductive reasoning, while the mathematical truth of the results of such activity are guaranteed in advance of their production. Hegel $(1816 / 1969$, p. 690) points out that induction

\begin{abstract}
in expressing that perception in order to become experience ought to be carried on to infinity, presupposes that the genus is in and for itself united with its determinateness. Therefore, strictly speaking, it rather presupposes its conclusion as something immediate. ... An experience that rests on induction is accepted as valid although the perception is admittedly incomplete; but the assumption that no contradictory instance of that experience can arise is only possible if the experience is true in and for itself. Thus the syllogism by induction, though indeed based on an immediacy, is not based on that immediacy on which it is supposed to be based, on the merely affirmative [seiende] immediacy of individuality, but on the immediacy which is in and for itself, the universal immediacy. (italics in the original)
\end{abstract}

Therefore, for induction to apparently operate as a reliable syllogism, it must be based on an immediacy which is always-already the universal immediacy.

The relation between the individual realisation of an object and its recognition as a legitimate instance of a universal notion is a problem of perennial concern to teachers. The question I now address is that of how Sketchpad is used to assert the universal in the case under discussion here. I have already briefly discussed how the drag test focuses attention on the universal defining features of the square.

The students' initial attempts at producing squares in the Sketchpad environment represent a contingent series of phenomenal experiences and constitute a form of reflection that Hegel refers to as positing reflection. Every square that is offered by a student is different from every other square offered by the student and by other students and so the series of phenomenally generated squares constitute a series of individuals. The series of squares produced by the students is a subset of the infinite class of squares that it is possible to produce in the Sketchpad environment by the range of methods used by the students.
The exceptional element of the class of such squares that has the effect of halting the infinite flow of squares at the level of phenomenal experience is the constructed square. The latter is an interesting object. On the one hand it is merely one among the set of possible phenomenally experienced squares; on the other hand, it is square-as-such, standing for the entire class of squares. In the expression of genus-species relations, the constructed square is genus and, at the same time, species. That is, of the class of squares, the constructed square is the exceptional element that completes the infinite series by being IT and so, paradoxically, being the final element. Each phenomenally experienced square, including the exceptional element, finds its ground in the exceptional element, so that the genus finds itself amongst its own species.

Once we have moved from an enumeration of the series of phenomenally experienced squares to the production, and addition, of the exceptional square that is both genus and species (square-as-such), then we have also moved from positing to external reflection. In Hegelian terms, the exceptional element-which is the square that remains a square when subjected to the drag test-achieves the status of concrete universal. That is, an individual through which shines the universal notion of square.

The use of the drawing-construction opposition encoded into Sketchpad fitted nicely with the lecturer's pedagogy, in which her engagement with students had them shift from the apparent certainty of their individual experiences to confronting themselves as lacking and (hopefully) on to a deeper engagement with the content of a lecture. Recall that the student as lacking is not asserted, or presumed, but has to be produced in the course of the flow of pedagogic exchanges between lecturer and students, or between text and students. What might be considered failure-the production of drawn rather than constructed squares by many students-is thus a legitimate element of the pedagogy modelled by the lecturer. The production of the series of squares is simultaneously the production of markers of another series-namely, the Van Hiele levels of geometrical thought-which is not immediately apparent to students but which is pointed out and alluded to at various moments in lectures. The production of a drawn square is not simply wrong. Rather, its presence is ultimately used to legitimate the deployment of the series of Van Hiele levels to read geometrical activity.

The infinite class of phenomenally produced squares, of which the students' particular series is an instance of positing reflection, is thus closed in a second way by means of the introduction of the Van Hiele levels. The shift from positing to external reflection is therefore repeated, but this time with respect to the lack that emerges as indexed by the individual squares that are produced. What we have is the production of a second exceptional element, viz., the Van Hiele level.

Using Lacan's (1966/2006) distinction between the 'subject of the enunciated' and the 'subject of the enunciation', one might argue that the two series generated by the pedagogic 
exchanges-the first concerning the production of squares and the second the production of Van Hiele level markers-have as their respective targets the subjects of the enunciated (squares) and of the enunciated (Van Hiele levels), the latter being the place from which the enunciation is presumed to be made. The subject of the enunciation is, precisely, the student-as-subject. A concern with the subject of the enunciation is, ultimately, a moral concern, its incessant question directed at the student being: 'Who are you?' Recall that, in his attempt at clarifying the structure of pedagogic discourse, Bernstein (1996) described pedagogic discourse as an instructional discourse embedded in a regulative discourse, with the regulative discourse being a moral discourse. The analysis of the shift from positing to external reflection with respect to two series (squares-as-squares and squares-as-levels) certainly resonates with Bernstein's proposition.

\section{Concluding remarks}

The structure of Session 2, in which the focus was on the production of a square in the Sketchpad environment, was repeated in the remaining five sessions. Firstly, some particular was introduced to the students who were then required to investigate it in a manner that promoted the production of a series of individuals. From the latter, conjectures were generated which were subsequently tested and 'verified' by some empirical procedure-usually measurement-which was taken to establish the truth of the matter. Simultaneously, by means of the drag test, Sketchpad designers seek to encourage and train users in the construction of geometrical objects that are exemplifications of the universal ideas pertinent to the particular geometrical objects of concern. However, there was inevitably a retreat into the empirical as measurement remained the preferred test of validity, so that the empirical and iconic regulative orientations emerged as dominant in the activity of students.

It was interesting to see that students spent inordinately long periods of time on tasks that they ought to have been able to complete in matters of minutes, being teachers of geometry. This was the case even in the later sessions, by which time they were very familiar with the Sketchpad interface.

The appeal to Van Hiele had the potential to influence students to develop ways of working with geometry that would privilege algorithmic and propositional regulative orientations, but the retreat to the empirical appeared to counteract that potential, so that Van Hiele ended up as a resource for registering the student as lacking rather than for assisting them in developing their geometrical thinking. In different terms, Van Hiele ended up as a resource for moralising the student.

\section{Acknowledgements}

The production of data for this article was funded by the National Research Foundation under Grant number FA2006031800003. Any opinions, findings and conclusions or recommendations expressed in this material are those of the author and do not reflect the views of the National Research Foundation. This publication is based on research that has been supported in part by the University of Cape Town's Research Committee (URC).

\section{Competing interests}

The author declares that he has no financial or personal relationships that may have inappropriately influenced him writing this article.

\section{References}

Bernstein, B. (1990). Class, codes and control. Volume 4: The structuring of pedagogic discourse. London: Routledge \& Kegan Paul.

Bernstein, B. (1996). Pedagogy, symbolic control and identity. Theory, research, critique. London: Routledge \& Kegan Paul.

Bloom, A.D. (Ed.). (1991). The Republic of Plato. New York, NY: Basic Books.

Chanan, S. (2001). The Geometer's Sketchpad, Version 4: Learning guide. Emeryville, CA: Key Curriculum Press.

Dowling, P. (2002). The sociology of mathematics education: Mathematical myths/ pedagogic texts. London: Routledge.

Dowling, P. (2009). Sociology as Method: Departures from the forensics of culture, text and knowledge. Rotterdam: Sense Publishers.

Greimas, A.J. (1968). The interaction of semiotic constraints. Yale French Studies, 41, 86-105.

Hegel, G.W.F. (1969). Science of logic. (A.V. Miller, Trans.). Amherst, NY: Humanity Books/George Allen \& Unwin. (Original work published 1816)

Hegel, G.W.F. (1975). Hegel's logic: Being part one of the encyclopaedia of the philosophical sciences. Oxford: Clarendon Press.

Hegel, G.W.F. (1977). Phenomenology of spirit. (A.V. Miller, Trans.). Oxford: Oxford University Press. (Original work published 1807)

Lacan, J. (2006). The subversion of the subject and the dialectic of desire in the Freudian unconscious. Écrits: The first complete edition in English. (B. Fink, Trans.) New York, NY: Norton. (Original work published 1966)

McCumber, J. (1993). The company of words: Hegel, language, and systematic philosophy. Evanston, IL: Northwestern University Press.

Piaget, J. (1995). Egocentric thought and sociocentric thought. Sociological studies. (L. Smith, Ed.). London: Routledge.

Pinkard, T. (2000). Hegel: A biography. Cambridge: Cambridge University Press.

Van Hiele, P.M. (1986). Structure and insight: a theory of mathematics education. Orlando, FL: Academic Press.

Žižek, S. (1994). The metastases of enjoyment: Six essays on woman and causality. London: Verso. 